\title{
Clinical Predictors of High Blood Eosinophils in Chronic Obstructive Pulmonary Disease
}

Mei Yang*

Ting Yang*

Xiaoou Li*

Diandian Li

Zenglin Liao

Yongchun Shen

Dan Xu

Lei Chen (D)

Fuqiang Wen (ID)

Department of Respiratory and Critical Care Medicine, West China Hospital, West China School of Medicine, Sichuan University, Chengdu, Sichuan, 6I004I, People's Republic of China

*These authors contributed equally to this work
Correspondence: Lei Chen; Fuqiang Wen Department of Respiratory and Critical Care Medicine, West China Hospital,

West China School of Medicine, Sichuan University, Chengdu, Sichuan, 61004I,

People's Republic of China

Email Ichens@126.com;

wenfuqiang@scu.edu.cn
Purpose: Elevated blood eosinophils have been implicated in chronic obstructive pulmonary disease (COPD) progression and exacerbation. We aim to investigate clinical predictors of high blood eosinophils in a Chinese COPD cohort.

Patients and Methods: We conducted a retrospective cohort study in Sichuan province, a Southwest province with high prevalence of COPD in China. All patients in this cohort were extracted from the Chinese Pulmonary Health study, a large cross-sectional study on COPD epidemiology in China. Demographics, personal and family history, living condition, spirometry and blood eosinophil counts were obtained. Univariate and multiple linear regression analyses were performed to determine predictors of high blood eosinophils.

Results: A total of 375 COPD patients were included in this cohort. The median absolute blood eosinophil count was 138.8 cells $/ \mu \mathrm{L}$, and the prevalence of COPD with high blood eosinophils was $66.7 \%$ and $14.7 \%$ when using the thresholds of 100 cells/ $\mu \mathrm{L}$ and 300 cells/ $\mu \mathrm{L}$, respectively. Univariate analyses indicated that male gender, lower body mass index, high-density lipoprotein (HDL), lower family income, raising pets and biomass use were significantly associated with high blood eosinophils $(p<0.05)$. Multiple linear regression model further revealed male gender (unstandardized coefficient $(B)=66.125,95 \%$ confidence intervals (CI) 16.350 to $115.900, \mathrm{p}=0.009)$, age $(\mathrm{B}=2.819,95 \% \mathrm{CI} 0.639$ to $5.000, \mathrm{p}=0.012)$ predicted high blood eosinophil level, whereas HDL $(B=-64.682,95 \%$ CI -123.451 to $-5.914, \mathrm{p}=0.031$ ) was a negative predictor for high blood eosinophils.

Conclusion: This retrospective cohort study suggests male gender, oldness and lower HDL could be clinical predictors of high blood eosinophils in Chinese COPD patients.

Keywords: chronic obstructive pulmonary disease, blood eosinophil count, high-density lipoprotein, predictor, retrospective study

\section{Introduction}

Chronic obstructive pulmonary disease (COPD), one of the primary health and economic burdens worldwide, has been widely accepted as a heterogeneous condition in terms of etiology, airway inflammation, exacerbation and response to inhaled corticosteroids (ICSs), etc. ${ }^{1-4}$ As blood eosinophil count has been extensively applied to describe COPD with eosinophilic inflammation, increased blood eosinophils have been reported to play important roles in COPD progression or exacerbation. ${ }^{5-7}$

A growing body of evidence demonstrated that COPD patients with elevated blood eosinophil count appeared to have a higher risk of acute exacerbation and favorable response to ICS therapy, ${ }^{8-14}$ which was documented in the 2021 Global Initiative for Chronic Obstructive Lung Disease (GOLD) strategy. ${ }^{15}$ The Copenhagen General Population study collected blood eosinophils at baseline, recorded future COPD 
exacerbations longitudinally, and observed a 1.76-fold increased risk of severe exacerbations in patients with high blood eosinophil level during a median of 3.3-year follow-up. ${ }^{8}$ Two other large longitudinal studies also demonstrated similar findings. ${ }^{9,10}$ A biologic clusters analysis further implied that there existed an eosinophilic-predominant exacerbation accounting for $28 \%$ of all COPD exacerbations, different from bacterial- or viral-predominant exacerbation. ${ }^{11}$ Additionally, the IMPACT trial observed an increased ICS benefit on moderate and severe COPD exacerbation, Transition Dyspnoea Index, St. George's Respiratory Questionnaire (SGRQ) total score, and forced expiratory volume in 1 second (FEV1), with elevated blood eosinophil counts. $^{12}$

It is worth noting that the mechanisms of high blood eosinophils in COPD are still undetermined. Th2 Signature score, an asthma-related gene expression metric, was reported to be increased in COPD, ${ }^{16}$ and correlated with production of interleukin-5 (IL-5), ${ }^{16,17}$ which was involved in activation, migration and effector functions of peripheral blood eosinophils. ${ }^{17-19}$ Recent studies revealed a prevalence of up to $45 \%$ of increased blood eosinophils in COPD without current asthma, and the potential features of this subgroup comprised higher body mass index (BMI), older age, male gender, former smoking, better quality of life and lung function. ${ }^{20-26}$ However, these results were mostly identified by univariate analyses, which needed further confirmation. Moreover, whether other factors associated with COPD, such as biomass use and history of respiratory disease, contribute to eosinophilic COPD remains unclear.

Therefore, in order to investigate the potential predictors for high blood eosinophils in COPD, we conducted a retrospective cohort study in Sichuan province, a Southwest province with high prevalence of COPD in China. All patients in this cohort were extracted from the Chinese Pulmonary Health $(\mathrm{CPH})$ study, a large crosssectional study on COPD epidemiology in China. ${ }^{27}$

\section{Materials and Methods \\ Study Design}

This retrospective cohort study was conducted in Sichuan province, which is located in Southwest China with a high COPD prevalence. All patients in this cohort were extracted from the $\mathrm{CPH}$ study, a large crosssectional study on COPD epidemiology in China. ${ }^{27}$ The $\mathrm{CPH}$ study applied a multistage stratified cluster sampling procedure to enroll a nationally representative sample of adults aged 20 years or older between June, 2012 and May, 2015. The clinical information associated with COPD was picked up, including demographics, personal history, family history, living condition, oral hygiene status, respiratory symptoms, COPD assessment test (CAT), drug therapy, spirometry and data on routine blood test, etc. Based on the recommendation in 2021 GOLD guideline, ${ }^{15}$ all patients were divided into three groups $(<100,100-300$ and $\geq 300$ cells $/ \mu \mathrm{L})$ by blood eosinophil thresholds of 100 cells $/ \mu \mathrm{L}$ and 300 cells $/ \mu \mathrm{L}$, followed by comparisons among the three groups. Then, univariate and multiple linear regression analyses were performed to identify predictors for blood eosinophil level. The reporting of this work was compliant with the Strengthening the Reporting of Observational studies in Epidemiology ( $\underline{\text { STROBE}}$ ) checklist. $^{28}$

\section{Patients}

Full inclusion and exclusion criteria for COPD patients have been described previously. ${ }^{27}$ According to the criteria, we included COPD patients aged $\geq 40$ years in Sichuan province, who provided available blood eosinophil counts. Patients with asthma, allergic rhinitis, or active tuberculosis were excluded.

\section{Ethical Statement}

Since this study was based on the data of previously published CPH study, ${ }^{27}$ the patient consents for publication were obtained, and the study protocol was approved by the Institutional Review Board of West China Hospital of Sichuan University, and the present study was conducted in accordance with the Declaration of Helsinki. Moreover, all authors confirmed that the data were anonymized or maintained with confidentiality, and were accountable for all aspects of the work in ensuring that questions related to the accuracy or integrity of any part of the work are appropriately investigated and resolved.

\section{Statistical Analysis}

For test of variable normality, we combined the histogram, Q-Q diagram and the Shapiro-Wilk test. Quantitative variables were expressed as mean $\pm \mathrm{SD}$ (standard deviation) when normally distributed, or median (interquartile range, IQR) when non-normally distributed. Qualitative variables were expressed as frequencies. Statistically significant difference was assessed by Chi-squared test or Fisher's exact test for qualitative variables, and for quantitative variables, 
the analysis of variance (ANOVA) or Kruskal-Wallis $H$-test was used. $\mathrm{P}$ value $<0.05$ was considered statistically significant. Univariate and multiple linear regression analyses were conducted to determine factors predicting high blood eosinophil count. Considering implications between blood eosinophils and some variables associated with COPD might be concealed by potential confounding factors in univariate analyses, we applied a higher threshold of statistical significance $(p=0.2)$ for entering variables in the multivariable model. ${ }^{29,30}$ As a result, variables with $p$ value $\leq 0.2$ in univariate analyses were regarded as potential predictors, which were chosen to enter simultaneously into the forced entry multivariable linear regression model. A multivariable regression model was constructed with the outcome in question as the dependent variable and potential predictors as the independent variables. It was presented with the constant (Y-intercept), the standardized regression coefficients (B), unstandardized $\mathrm{B}$ and their $95 \%$ confidence intervals (CIs). P value $<0.05$ was used to define the statistical significance of the final model. The amount of variance accounted for by the final model was expressed as $\mathrm{R}^{2}$ and the model was checked for collinearity through the variance inflation factor. The statistical tool used was SPSS (version 19 for Windows, IBM SPSS Statistics, IBM Corporation).

\section{Results}

\section{Baseline Characteristics of Study Population}

In the CPH study, there were 548 COPD patients aged $\geq 40$ years in Sichuan province, among which 402 COPD patients provided blood eosinophil counts. However, 27 patients were once diagnosed with asthma or allergic rhinitis by doctors and were excluded in the present study. Therefore, according to the eligibility criteria, 375 COPD patients were finally included in this study, with a mean age of 63.2 (SD 10.8) years, $61.9 \%$ males, $46.7 \%$ smokers, and a mean FEV1\% predicted of 89.4 (SD 21.5) \%. Median absolute blood eosinophil count was 138.8 cells $/ \mu \mathrm{L}$ (IQR 82.3-226.6) in all COPD patients, with 156.0 cells/ $\mu \mathrm{L}$ (IQR 97.9-246.0) in males and 113.4 cells $/ \mu \mathrm{L}$ (IQR 69.4-197.5) in females. There were $125(<100$ cells $/ \mu \mathrm{L}), 195(100-300$ cells $/ \mu \mathrm{L})$ and 55 ( $\geq 300$ cells $/ \mu \mathrm{L})$ patients in the three groups stratified by absolute blood eosinophil counts, which indicated a prevalence of COPD with high blood eosinophils in this cohort was $66.7 \%$ and $14.7 \%$ when using the thresholds of 100 cells $/ \mu \mathrm{L}$ and 300 cells $/ \mu \mathrm{L}$, respectively. More characteristics of the study population are shown in Table 1. However, the medical information was missed because of incomplete records in the $\mathrm{CPH}$ study.

\section{Factors Associated with Blood Eosinophil Count in COPD}

Comparisons among the three groups demonstrated that male gender $(\mathrm{p}<0.001)$, lower BMI $(\mathrm{p}=0.001)$ and family income $(\mathrm{p}=0.012)$, raising pets $(\mathrm{p}=0.043)$, biomass use $(\mathrm{p}=0.003)$, higher blood leukocytes $(\mathrm{p}<0.001)$ and lower blood neutrophils $(\mathrm{p}<0.001)$ were significantly different, indicative of some potential correlators for increased blood eosinophils (Table 1). However, no statistical significance regarding smoking status, pulmonary function, and duration of biomass exposure was revealed (Table 1). Furthermore, in the univariate linear regression analysis, male gender $(\mathrm{p}=0.022)$, raising pets $(\mathrm{p}=0.038)$, biomass use $(\mathrm{p}=0.002)$, lower high-density lipoprotein (HDL, $\mathrm{p}=0.037)$ and BMI $(\mathrm{p}=0.016)$ were significantly correlated with high blood eosinophils (Table 2).

\section{Clinical Predictors of High Blood Eosinophils in COPD}

Based on the univariate analyses, in addition to age, nine potential predictors with $\mathrm{p}$ value $\leq 0.2$, comprising male gender, raising pets, biomass use, former smoking, family income, BMI, total cholesterol (TC), HDL and low-density lipoprotein (LDL) were included in the multiple linear regression model (Table 3). As a result, determined predictors for high blood eosinophils were male gender $(\mathrm{B}=66.125,95 \% \mathrm{CI}$ 16.350 to $115.900, \mathrm{p}=0.009)$, age $(\mathrm{B}=2.819,95 \% \mathrm{CI} 0.639$ to $5.000, \mathrm{p}=0.012)$ and lower HDL $(\mathrm{B}=-64.682,95 \% \mathrm{CI}$ -123.451 to $-5.914, \mathrm{p}=0.031)$. The final model explained $11.4 \%\left(\mathrm{R}^{2}=0.114\right.$, adjusted $\left.\mathrm{R}^{2}=0.067\right)$ of the variance in blood eosinophil count $(\mathrm{F}=2.431, \mathrm{p}=0.010)$.

\section{Discussion}

The present study retrospectively investigated potential predictors of high blood eosinophils in COPD, indicating two important findings: 1) in this cohort, the median absolute blood eosinophil count was 138.8 cells $/ \mu \mathrm{L}$ and the prevalence of COPD with high blood eosinophils was $66.7 \%$ and $14.7 \%$ when using the thresholds of 100 cells/ $\mu \mathrm{L}$ and 300 cells $/ \mu \mathrm{L}$, respectively; 2 ) after being adjusted by raising pets, biomass use, former smoking, family income, BMI, LDL and TC, factors including male gender, 
Table I Comparison of Clinical Characteristics in COPD Patients with Different Blood Eosinophil Levels

\begin{tabular}{|c|c|c|c|c|}
\hline & $<100$ (125) Cells/ $/ \mu \mathrm{L}$ & $100-300$ (195) cells/ $\mu \mathrm{L}$ & $\geq 300$ (55) cells $/ \mu \mathrm{L}$ & $\mathbf{P}$ \\
\hline Male & $60(48.0)$ & $134(68.7)$ & $38(69.1)$ & $<0.001 *$ \\
\hline Female & $65(52.0)$ & $61(31.3)$ & $17(30.9)$ & $<0.001 *$ \\
\hline Age ( $\geq 40$ years) & $62.4 \pm 11.5$ & $63.1 \pm 10.4$ & $65.5 \pm 10.1$ & 0.195 \\
\hline BMI & $24.5 \pm 3.4$ & $24.1 \pm 2.9$ & $22.7 \pm 2.5$ & $0.00 I^{*}$ \\
\hline Family income $\left(10^{4}\right.$ yuan/year $)$ & $2.0(1.0,3.0)$ & $2.0(1.0,4.0)$ & $1.0(0.5,3.0)$ & $0.012^{*}$ \\
\hline Raising pets & $55(44.4)$ & $98(51.0)$ & $35(64.8)$ & $0.043 *$ \\
\hline Biomass use ${ }^{a}$ & $53(42.7)$ & $97(50.8)$ & $38(70.4)$ & $0.003 *$ \\
\hline Duration of biomass exposure ${ }^{b}$ & $40.4 \pm 17.0$ & $38.3 \pm 18.6$ & $42.1 \pm 17.2$ & 0.511 \\
\hline \multicolumn{5}{|l|}{ Smoking status } \\
\hline Current smoker & $33(26.4)$ & $73(37.4)$ & $19(34.5)$ & 0.089 \\
\hline Former smoker & $13(10.4)$ & 27 (13.9) & $10(18.2)$ & - \\
\hline Never smoking & $79(63.2)$ & $95(48.7)$ & $26(47.3)$ & - \\
\hline Bromopnea & $13(10.7)$ & $22(11.6)$ & $5(9.6)$ & 0.913 \\
\hline Teeth problem ${ }^{c}$ & $88(71.5)$ & $125(65.1)$ & $36(66.7)$ & 0.488 \\
\hline Periodontitis $^{\mathrm{d}}$ & $19(15.3)$ & $22(11.5)$ & $7(13.2)$ & 0.608 \\
\hline CAT & $7.5(3.0,14.0)$ & $6.0(2.0,11.25)$ & $5.0(2.0,11.0)$ & 0.262 \\
\hline NEU\% & $62.2(57.1,68.9)$ & $60.1(54.9,66.5)$ & $57.0(53.0,62.0)$ & $<0.001 *$ \\
\hline WBC $\left(10^{9} / \mathrm{L}\right)$ & $5.4(4.6,6.4)$ & $6.0(5.1,7.3)$ & $6.4(5.7,7.2)$ & $<0.001 *$ \\
\hline TG (mmol/L) & I.4 (I.I, I.8) & I.3 (I.I, I.8) & $1.6(1.2,1.7)$ & 0.474 \\
\hline $\mathrm{TC}(\mathrm{mmol} / \mathrm{L})$ & $4.9(4.5,5.7)$ & $4.8(4.2,5.5)$ & $5.4(4.1,6.1)$ & 0.169 \\
\hline $\mathrm{HDL}(\mathrm{mmol} / \mathrm{L})$ & $1.5(1.3,1.9)$ & $1.5(1.3,1.7)$ & $1.5(1.2,1.8)$ & 0.642 \\
\hline LDL (mmol/L) & $2.7 \pm 0.8$ & $2.6 \pm 0.7$ & $2.9 \pm 0.9$ & 0.175 \\
\hline FEVI\% predicted (\%) & $90.8 \pm 22.6$ & $89.0 \pm 20.7$ & $88.0 \pm 22.0$ & 0.712 \\
\hline \multicolumn{5}{|l|}{ Pre-bronchodilator } \\
\hline PEF (L/s) & $4.7(3.0,6.2)$ & $4.6(3.5,6.1)$ & $4.4(3.3,6.0)$ & 0.710 \\
\hline FEVI: FVC (\%) & $63.3(57.7,67.8)$ & $63.1(56.7,63.6)$ & $60.0(51.6,66.1)$ & 0.107 \\
\hline \multicolumn{5}{|l|}{ Post-bronchodilator } \\
\hline PEF (L/s) & $4.8(3.4,6.5)$ & $5.0(3.9,6.3)$ & $4.6(3.3,6.6)$ & 0.423 \\
\hline FEVI: FVC (\%) & $65.5(59.3,68.0)$ & $64 . I(57.3,67.9)$ & $63.1(51.9,67.3)$ & 0.143 \\
\hline GOLD stage $\leq$ I & $93(74.4)$ & | 40 (7|.8) & $40(72.7)$ & 0.878 \\
\hline
\end{tabular}

Notes: Data are presented as $\mathrm{n}(\%)$, mean $\pm \mathrm{SD}$ or median (interquartile range). ${ }^{*} \mathrm{p}<0.05$. ${ }^{\mathrm{a}}$ Defined as using woody fuels or animal waste for cooking or heating during the past 6 months or longer. ${ }^{b}$ Defined as consecutive years of biomass exposure. 'Defined as having at least one of the following conditions in the past one year, including swollen gums, gingival bleeding, toothache, tooth losing and damaging. ${ }^{\mathrm{d} D e f i n e d}$ as being diagnosed with periodontitis by dentists.

Abbreviations: COPD, chronic obstructive pulmonary disease; BMI, body mass index; CAT, COPD assessment test; NEU\%, percentage of neutrophils; WBC, leukocyte count; TG, triglycerides; TC, total cholesterol; HDL, high-density lipoprotein; LDL, low-density lipoprotein; FEVI, forced expiratory volume in I second; PEF, peak expiratory flow; FVC, forced vital capacity. 
Table 2 Factors Associated with Blood Eosinophil Count in COPD Patients According to Univariate Linear Regression Analysis

\begin{tabular}{|c|c|c|c|c|c|}
\hline \multirow[t]{2}{*}{ Factors } & \multicolumn{2}{|c|}{ Unstandardized Coefficients } & \multirow{2}{*}{$\frac{\text { Standardized Coefficients }}{\text { Beta }}$} & \multirow[t]{2}{*}{$P$ value } & \multirow[t]{2}{*}{ Adjusted $\mathbf{R}^{2}$} \\
\hline & Beta & $95 \% \mathrm{Cl}$ & & & \\
\hline Age ( $\geq 40$ years) & 0.934 & -0.944 to 2.813 & 0.051 & 0.329 & 0.000 \\
\hline Male & 44.312 & 6.556 to 82.067 & 0.119 & $0.022 *$ & 0.011 \\
\hline BMI & -7.716 & -13.989 to -1.443 & -0.124 & $0.016^{*}$ & 0.013 \\
\hline Family income & -4.552 & -11.663 to 2.559 & -0.067 & 0.209 & 0.002 \\
\hline Raising pets & 43.130 & 2.423 to 83.838 & 0.108 & $0.038^{*}$ & 0.009 \\
\hline Biomass use & 64.788 & 24.307 to 105.268 & 0.162 & $0.002 *$ & 0.024 \\
\hline Duration of biomass exposure & 0.484 & -1.445 to 2.413 & 0.037 & 0.62 & -0.004 \\
\hline Former smoking & 45.279 & -5.307 to 95.865 & 0.091 & 0.079 & 0.006 \\
\hline Bromopnea & 15.726 & -50.507 to 81.959 & 0.025 & 0.641 & -0.002 \\
\hline Teeth problem & 13.815 & -29.885 to 57.516 & 0.032 & 0.535 & -0.002 \\
\hline Periodontitis & 37.972 & -31.547 to 107.490 & 0.056 & 0.283 & 0.056 \\
\hline TG & 4.318 & -28.002 to 36.638 & 0.018 & 0.793 & -0.004 \\
\hline TC & -10.048 & -36.020 to 15.924 & -0.053 & 0.447 & -0.002 \\
\hline HDL & -58.688 & -113.664 to -3.713 & -0.144 & $0.037^{*}$ & 0.016 \\
\hline LDL & -3.744 & -38.924 to 31.435 & -0.014 & 0.834 & -0.005 \\
\hline
\end{tabular}

Note: $*_{p}<0.05$

Table 3 Factors Associated with Blood Eosinophil Count in COPD Patients According to Multivariable Linear Regression Analysis

\begin{tabular}{|l|c|c|c|c|}
\hline \multirow{2}{*}{ Independent Variables } & \multicolumn{2}{|c|}{ Unstandardized Coefficients } & Standardized Coefficients & \multirow{2}{*}{ P value } \\
\cline { 2 - 5 } & Beta & $\mathbf{9 5 \%} \mathbf{C l}$ & Beta & 0.486 \\
\hline Constant & 98.729 & -180.317 to 377.775 & - & $0.012^{*}$ \\
Age $(\geq 40$ years) & 2.819 & 0.639 to 5.000 & 0.183 & $0.009^{*}$ \\
Male & 66.125 & 16.350 to 115.900 & 0.191 & 0.188 \\
BMl & -4.888 & -12.186 to 2.409 & -0.093 & 0.728 \\
Family income & -1.383 & -9.204 to 6.438 & -0.027 & 0.478 \\
Raising pets & 41.957 & 3.964 to 79.951 & 0.137 & 0.313 \\
Biomass use & 27.373 & -25.966 to 80.712 & 0.083 & 0.769 \\
Former smoking & 10.545 & -60.298 to 81.388 & 0.021 & 0.832 \\
TC & 3.267 & -27.088 to 33.622 & 0.025 & $0.03 I^{*}$ \\
HDL & -64.682 & -123.451 to -5.914 & -0.179 & 0.536 \\
LDL & 13.928 & -30.342 to 58.199 & 0.069 & \\
\hline
\end{tabular}

Notes: $\mathrm{R}^{2}=0.114$, adjusted $\mathrm{R}^{2}=0.067$. Adjusted for age, male gender, $\mathrm{BMI}$, family income, raising pets, biomass use, former smoking, $T C, H D L$ and $L D L$. * $\mathrm{p}<0.05$.

age and lower HDL were determined as predictors for higher blood eosinophils in COPD patients from the Chinese cohort. However, the correlation between higher BMI and increased blood eosinophils implied by other studies was not validated in this study. ${ }^{20,26}$

Epidemiological evidence demonstrated that eosinophilic COPD could be a specific phenotype. However, the prevalence of eosinophilic inflammation in COPD varied with different thresholds. In post-hoc analyses of clinical trials, the prevalence of high blood eosinophils in COPD was more than $45 \%$ according to the threshold of
$2 \%,{ }^{20,22,24}$ whereas it was less than $20 \%$ when using the cut-off of 300 cells $/ \mu \mathrm{L},,^{31,32}$ similar to the results in this cohort study.

Current evidence concerning COPD with eosinophilic inflammation was mostly based on clinical phenotypic studies. ${ }^{4}$ The positive association between male gender and blood eosinophils in COPD has been well established in considerable reports, ${ }^{20,25,26}$ even though these results were almost identified by univariate analyses. Our study further confirmed the relationship by multivariable analyses, emphasizing an existed gender-related difference 
regarding blood eosinophil level. Old age is a vital factor associated with the development and progression of COPD and its exacerbation. ${ }^{15}$ In this cohort study, we found oldness was a predictor for high blood eosinophils, similar to two other cross-sectional studies that indicated COPD patients with higher blood eosinophil counts were apparently older. ${ }^{20,33}$ However, two other reports did not suggest the same relationship between age and blood eosinophils. ${ }^{22,24}$ Consequently, the underlying reasons for the different results on the link between age and blood eosinophils in COPD need further verification.

An inverse association between HDL cholesterol and blood eosinophil counts has been reported in other crosssectional studies. ${ }^{34,35}$ Our results further provided confirmatory evidence in a Chinese cohort. Mechanistic studies have demonstrated HDL could regulate proliferation and differentiation of hematopoietic stem cells through a cholesterol efflux-dependent manner involving ABCA1, ABCG1 and liver $X$ receptors. ${ }^{36,37}$ HDL deficiency resulted in peripheral leukocytosis, including blood eosinophilia, ${ }^{38}$ and a $1 \mathrm{mmol} / \mathrm{L}$ HDL cholesterol lowering was reported to be correlated with $14.8 \%$ higher eosinophils. ${ }^{34}$ Given the imbalance in lipid profile in COPD implied by previous studies, ${ }^{39-41}$ it is imperative to explore whether the change in HDL level plays a role in eosinophilic COPD, and whether treatment for lower HDL in COPD is beneficial to reduce eosinophil-predominant exacerbation.

A real-world research demonstrated higher BMI was correlated with pulmonary function, lower inflammation levels and acute exacerbations, drawing attention to the impact of BMI on COPD management. ${ }^{42}$ However, in our study, the relationship between lower BMI and higher blood eosinophils was unexpectedly revealed in the initial univariate analysis, and after adjusting potential confounding factors, statistical significance of BMI was not observed, and it was inconsistent with other relevant reports, ${ }^{20,25,26}$ in which COPD with increased blood eosinophils was characterized by higher BMI. Different ethnic populations might account for this controversial result, and more studies in different populations are needed to verify the relationship between BMI and blood eosinophils.

Several limitations should be noticed in this study. First, the baseline information for all patients was not fully provided. For example, the medical information was missed because of incomplete records in the CPH study. Second, there could exist some possibility that the patients with asthma were not fully excluded from the analyses because of the lack of some related information. To avoid the potential impact, we excluded younger patients aged $<40$ years, a high-risk subgroup of asthma. ${ }^{43}$ Third, the diagnosis of COPD in this study was based only on spirometry tests. There could exist some overdiagnosis of COPD in this study. Fourth, potential recall biases were inevitable in a retrospective study.

In summary, this retrospective cohort study suggested and identified male gender, oldness and lower HDL could be clinical predictors of increased blood eosinophils in Chinese COPD patients. However, large prospective cohort studies are warranted to validate the present findings.

\section{Data Sharing Statement}

The datasets generated and analyzed during the present study are available from the corresponding authors on reasonable requests.

\section{Consent for Publication Statement}

Details of any images, videos, recordings, etc. can be published, and all authors have been shown the article contents to be published. Authors are prepared to provide copies of signed consent forms to the journal editorial office if requested.

\section{Acknowledgment}

This work was supported in part by grants ZYGD18006 and ZYJC18012 from the $1 \cdot 3 \cdot 5$ project for disciplines of excellence, West China Hospital of Sichuan University, and grants 2016YFC0903600 and 2016YFC0901100 from the National Key Research and Development Program of China.

\section{Author Contributions}

All authors contributed to the conception, study design, execution, acquisition of data, data analysis, drafting or revising the article, have agreed on the journal to which the article will be submitted, gave final approval of the version to be published, and agreed to be accountable for all aspects of the work.

\section{Disclosure}

The authors report no conflicts of interest in this work.

\section{References}

1. Ortega H, Llanos JP, Lafeuille MH, et al. Burden of disease associated with a COPD eosinophilic phenotype. Int J Chron Obstruct Pulmon Dis. 2018;13:2425-2433. doi:10.2147/COPD.S170995 
2. Higham A, Quinn AM, Cançado JED, et al. The pathology of small airways disease in COPD: historical aspects and future directions. Respir Res. 2019;20(1):49. doi:10.1186/s12931-019-1017-y

3. Han MK, Agusti A, Calverley PM, et al. Chronic obstructive pulmonary disease phenotypes: the future of COPD. Am J Respir Crit Care Med. 2010;182(5):598-604. doi:10.1164/rccm.200912-1843CC

4. Koblizek V, Milenkovic B, Barczyk A, et al. Phenotypes of COPD patients with a smoking history in central and Eastern Europe: the POPE Study. Eur Respir J. 2017;49(5):5. doi:10.1183/ 13993003.01446-2016

5. Barnes PJ. Inflammatory mechanisms in patients with chronic obstructive pulmonary disease. J Allergy Clin Immunol. 2016;138 (1):16-27.

6. Roy K, Smith J, Kolsum U, et al. COPD phenotype description using principal components analysis. Respir Res. 2009;10(1):41. doi:10.1186/1465-9921-10-41

7. George L, Taylor AR, Esteve-Codina A, et al. Blood eosinophil count and airway epithelial transcriptome relationships in COPD versus asthma. Allergy. 2020;75(2):370-380. doi:10.1111/all.14016

8. Vedel-Krogh S, Nielsen SF, Lange P, et al. Blood eosinophils and exacerbations in chronic obstructive pulmonary disease. The Copenhagen General Population Study. Am J Respir Crit Care Med. 2016;193(9):965-974. doi:10.1164/rccm.201509-1869OC

9. Kerkhof M, Sonnappa S, Postma DS, et al. Blood eosinophil count and exacerbation risk in patients with COPD. Eur Respir J. 2017;50 (1): 1700761.

10. Yun JH, Lamb A, Chase R, et al. Blood eosinophil count thresholds and exacerbations in patients with chronic obstructive pulmonary disease. $J$ Allergy Clin Immunol. 2018;141(6):2037-47.e10. doi:10.1016/j.jaci.2018.04.010

11. Bafadhel M, McKenna S, Terry S, et al. Acute exacerbations of chronic obstructive pulmonary disease: identification of biologic clusters and their biomarkers. Am J Respir Crit Care Med. 2011;184(6):662-671. doi:10.1164/rccm.201104-0597OC

12. Pascoe S, Barnes N, Brusselle G, et al. Blood eosinophils and treatment response with triple and dual combination therapy in chronic obstructive pulmonary disease: analysis of the IMPACT trial. Lancet Respir Med. 2019;7(9):745-756. doi:10.1016/S2213-2600(19)30190-0

13. Pavord ID, Lettis S, Locantore $\mathrm{N}$, et al. Blood eosinophils and inhaled corticosteroid/long-acting $\beta-2$ agonist efficacy in COPD. Thorax. 2016;71(2):118-125. doi:10.1136/thoraxjnl-2015-207021

14. Pascoe S, Locantore N, Dransfield MT, et al. Blood eosinophil counts, exacerbations, and response to the addition of inhaled fluticasone furoate to vilanterol in patients with chronic obstructive pulmonary disease: a secondary analysis of data from two parallel randomised controlled trials. Lancet Respir Med. 2015;3(6):435-442. doi:10.1016/S2213-2600(15)00106-X

15. Global Initiative for Chronic Obstructive Lung Diseases. Global strategy for the diagnosis, management and prevention of chronic obstructive pulmonary disease (2021 report). Available from: https:// goldcopd.org/2021-gold-reports/. Accessed August 7, 2021.

16. Christenson SA, Steiling K, van den Berge M, et al; Asthma-COPD overlap. Clinical relevance of genomic signatures of type 2 inflammation in chronic obstructive pulmonary disease. Am J Respir Crit Care Med. 2015;191(7):758-766. doi:10.1164/rccm.201408-1458OC

17. Tashkin DP, Wechsler ME. Role of eosinophils in airway inflammation of chronic obstructive pulmonary disease. Int J Chron Obstruct Pulmon Dis. 2018;13:335-349. doi:10.2147/COPD.S152291

18. Bafadhel M, Pavord ID, Russell REK. Eosinophils in COPD: just another biomarker? Lancet Respir Med. 2017;5(9):747-759. doi:10.1016/S2213-2600(17)30217-5

19. George L, Brightling CE. Eosinophilic airway inflammation: role in asthma and chronic obstructive pulmonary disease. Ther Adv Chronic Dis. 2016;7(1):34-51. doi:10.1177/2040622315609251
20. Singh D, Kolsum U, Brightling C, et al. Eosinophilic inflammation in COPD: prevalence and clinical characteristics. Eur Respir J. 2014;44 (6):1697-1700. doi:10.1183/09031936.00162414

21. Oshagbemi O, Franssen F, Braeken D, et al. Blood eosinophilia, use of inhaled corticosteroids, and risk of COPD exacerbations and mortality. Pharmacoepidemiol Drug Saf. 2018;27(11):1191-1199. doi:10.1002/pds. 4655

22. Zysman M, Deslee G, Caillaud D, et al. Relationship between blood eosinophils, clinical characteristics, and mortality in patients with COPD. Int J Chron Obstruct Pulmon Dis. 2017;12:1819-1824. doi:10.2147/COPD.S129787

23. Kolsum U, Ravi A, Hitchen P, et al. Clinical characteristics of eosinophilic COPD versus COPD patients with a history of asthma. Respir Res. 2017;18(1):73. doi:10.1186/s12931-017-0559-0

24. Oh Y, Lee K, Hong Y, et al. Blood eosinophil count as a prognostic biomarker in COPD. Int $J$ Chron Obstruct Pulmon Dis. 2018;13:3589-3596. doi:10.2147/COPD.S179734

25. Wu H, Zhuo K, Cheng D. Prevalence and baseline clinical characteristics of eosinophilic chronic obstructive pulmonary disease: a meta-analysis and systematic review. Front Med. 2019;6:282. doi:10.3389/fmed.2019.00282

26. Landis S, Suruki R, Maskell J, et al. Demographic and clinical characteristics of COPD patients at different blood eosinophil levels in the UK clinical practice research datalink. COPD. 2018;15 (2):177-184. doi:10.1080/15412555.2018.1441275

27. Wang $\mathrm{C}, \mathrm{Xu}$ J, Yang L, et al. Prevalence and risk factors of chronic obstructive pulmonary disease in China (the China Pulmonary Health [CPH] study): a national cross-sectional study. Lancet. 2018;391 (10131):1706-1717. doi:10.1016/S0140-6736(18)30841-9

28. von Elm E, Altman DG, Egger M, et al. The Strengthening the Reporting of Observational Studies in Epidemiology (STROBE) statement: guidelines for reporting observational studies. Lancet. 2007;370(9596):1453-1457. doi:10.1016/S0140-6736(07)61 602-X

29. Van Ryswyk E, Anderson CS, Antic NA, et al. Predictors of long-term adherence to continuous positive airway pressure in patients with obstructive sleep apnea and cardiovascular disease. Sleep. 2019;42(10). doi:10.1093/sleep/zsz152

30. Colonna AL, Griffiths TM, Robison DC, et al. Cholecystostomy: are we using it correctly? Am J Surg. 2019;217(6):1010-1015. doi:10.1016/j.amjsurg.2019.04.002

31. Casanova C, Celli BR, De-torres JP, et al. Prevalence of persistent blood eosinophilia: relation to outcomes in patients with COPD. Eur Respir J. 2017;50(5):1701162. doi:10.1183/13993003.01162-2017

32. Shin SH, Park HY, Kang D, et al. Serial blood eosinophils and clinical outcome in patients with chronic obstructive pulmonary disease. Respir Res. 2018;19(1):134. doi:10.1186/s12931-018-0840-x

33. DiSantostefano R, Hinds D, Le H, et al. Relationship between blood eosinophils and clinical characteristics in a cross-sectional study of a US population-based COPD cohort. Respir Med. 2016;112:88-96. doi:10.1016/j.rmed.2016.01.013

34. Harsløf M, Pedersen KM, Nordestgaard BG, et al. Low high-density lipoprotein cholesterol and high white blood cell counts: a Mendelian Randomization Study. Arterioscler Thromb Vasc Biol. 2021;41 (2):976-987. doi:10.1161/ATVBAHA.120.314983

35. Tucker B, Sawant S, McDonald H, et al. The association of serum lipid and lipoprotein levels with total and differential leukocyte counts: results of a cross-sectional and longitudinal analysis of the UK biobank. Atherosclerosis. 2021;319:1-9. doi:10.1016/j. atherosclerosis.2020.12.016

36. Yvan-Charvet L, Pagler T, Gautier E, et al. ATP-binding cassette transporters and HDL suppress hematopoietic stem cell proliferation. Science. 2010;328(5986):1689-1693. doi:10.1126/ science. 1189731 
37. Westerterp M, Gourion-Arsiquaud S, Murphy AJ, et al. Regulation of hematopoietic stem and progenitor cell mobilization by cholesterol efflux pathways. Cell Stem Cell. 2012;11(2):195-206. doi:10.1016/j. stem.2012.04.024

38. Feng Y, Schouteden S, Geenens R, et al. Hematopoietic stem/progenitor cell proliferation and differentiation is differentially regulated by high-density and low-density lipoproteins in mice. PLoS One. 2012;7(11):e47286. doi:10.1371/journal.pone.0047286

39. Markelić I, Hlapčić I, Rogić D, et al. Lipid profile and atherogenic indices in patients with stable chronic obstructive pulmonary disease. Nutr Metab Cardiovasc Dis. 2021;31(1):153-161. doi:10.1016/j. numecd.2020.07.039

40. Reed RM, Iacono A, DeFilippis A, et al. Advanced chronic obstructive pulmonary disease is associated with high levels of high-density lipoprotein cholesterol. J Heart Lung Transplant. 2011;30 (6):674-678. doi:10.1016/j.healun.2010.12.010
41. Tisi GM, Conrique A, Barrett-Connor E, et al. Increased high density lipoprotein cholesterol in obstructive pulmonary disease (predominant emphysematous type). Metabolism. 1981;30(4):340-346. doi:10.1016/0026-0495(81)90113-X

42. Wu Z, Yang D, Ge Z, et al. Body mass index of patients with chronic obstructive pulmonary disease is associated with pulmonary function and exacerbations: a retrospective real world research. J Thorac Dis. 2018;10(8):340-346. doi:10.21037/jtd.2018.08.67

43. Huang K, Yang T, Xu J, et al. Prevalence, risk factors, and management of asthma in China: a national cross-sectional study. Lancet. 2019;394(10196):407-418. doi:10.1016/S0140-6736(19)31147-X

International Journal of Chronic Obstructive Pulmonary Disease

\section{Publish your work in this journal}

The International Journal of COPD is an international, peer-reviewed journal of therapeutics and pharmacology focusing on concise rapid reporting of clinical studies and reviews in COPD. Special focus is given to the pathophysiological processes underlying the disease, intervention programs, patient focused education, and self management protocols. This journal is indexed on PubMed Central, MedLine and CAS. The manuscript management system is completely online and includes a very quick and fair peer-review system, which is all easy to use. Visit http://www.dovepress.com/testimonials.php to read real quotes from published authors.

Submit your manuscript here: https://www.dovepress.com/international-journal-of-chronic-obstructive-pulmonary-disease-journal 